\title{
A Novel Basal Promoter Element Is Required for Expression of the Rat Tyrosine Hydroxylase Gene
}

\author{
Swati Patankar, ${ }^{1}$ Meredith Lazaroff,, ${ }^{2}$ Sung Ok Yoon, ${ }^{1}$ and Dona M. Chikaraishi ${ }^{1,2}$ \\ Departments of ${ }^{1}$ Molecular Biology and Microbiology and ${ }^{2}$ Neuroscience, Tufts University School of Medicine, Boston, \\ Massachusetts 02111
}

Transcription of the rat tyrosine hydroxylase $(\mathrm{TH})$ gene is controlled by enhancer sequences in its $5^{\prime}$ flanking region; these enhancers include the AP1, dyad, and cAMP response element (CRE) motifs. We show that a novel basal promoter element (-17 GCCTGCCTGGCGA -5$)$ positioned between the TATA box and +1 works in conjunction with the upstream AP1-dyad and CRE enhancers but cannot support transcription by itself. A mutation of this element, termed partial dyad, reduces basal expression of a reporter gene in $\mathrm{TH}$-positive cell lines and $\mathrm{TH}$-negative lines but has no effect on CAMP- or $\mathrm{KCl}$-induced expression. A double mutant at positions -17 and -11 of the partial dyad reduces transcriptional activation by $80 \%$. Con- versely, insertion of this element into a heterologous promoter restores basal expression to levels mediated by the native $\mathrm{TH}$ promoter. The partial dyad is a novel activational element that is required for full expression of the $\mathrm{TH}$ gene and may assist in the function of the AP1, dyad, and CRE motifs and also other enhancers further upstream. Hence, the rat $\mathrm{TH}$ gene is unusual in that its enhancers will not function with a heterologous promoter but require a specific $\mathrm{TH}$ promoter sequence for full activation.

Key words: tyrosine hydroxylase; promoter; CRE; TATA box; AP1; cAMP; depolarization
Catecholamines play obligate trophic roles in development (Kobayashi et al., 1995; Rios et al., 1995; Zhou et al., 1995) and are used later as neurotransmitters in the CNS and in the peripheral nervous system (PNS). All catecholaminergic cells express the first and rate-limiting enzyme in catecholamine biosynthesis: tyrosine hydroxylase $(\mathrm{TH})$. In the mature mammal $\mathrm{TH}$ is expressed in discrete areas of the hypothalamus, midbrain, brainstem, and olfactory bulb in the CNS; the sympathetic ganglia, paraganglia, and adrenal chromaffin cells are TH-positive in the periphery (Bjorklund and Lindvall, 1984). This highly specific, yet diverse, localization makes $\mathrm{TH}$ a useful model to study neuronal gene expression.

Studies in transgenic mice indicate that large $5^{\prime}$ regions of the rat $\mathrm{TH}$ gene [4.5-9 kilobases $(\mathrm{kb})$ ] are required for accurate cell type-specific expression (Bannerjee et al., 1992, 1994; Min et al., 1994). These long $5^{\prime}$ flanking regions direct transcription that is regulated appropriately during development and in the adult animal. In embryonic mice transcription of a chloramphenicol acetyl transferase (CAT) reporter gene is induced by the floor plate in a manner similar to the endogenous TH gene (Hynes et al., 1995). In olfactory bulbs of postnatal transgenic mice, transcription of CAT follows the same developmental time course as

Received Oct. 21, 1996; revised Feb. 28, 1997; accepted March 19, 1997.

This work was supported by National Institutes of Health Grant NS22675 to D.M.C. We thank Dr. K. S. Kim for supplying the PC12 and SK-N-BE(2)C cell lines, Dr. Dale Hunter for critical reading of this manuscript, and Barbara D'Angelo for assistance in preparation of this manuscript.

Correspondence should be addressed to Dr. Dona M. Chikaraishi at her present address: Department of Neurobiology, 427G Bryan Research Building, Duke University Medical Center, Box 3209, Durham, NC 27710.

Dr. Patankar's present address: Department of Tropical Public Health, Harvard School of Public Health, 665 Huntington Avenue, Boston, MA 02115.

Dr. Lazaroff's present address: Department of Physiology, University of Colorado Health Sciences Center, Denver, CO 80206.

Dr. Yoon's present address: Department of Cell Biology and Anatomy, Cornell University Medical College, 1300 York Avenue, New York, NY 10021.

Copyright (C) 1997 Society for Neuroscience $0270-6474 / 97 / 174076-11 \$ 05.00 / 0$ that of TH and is under the same trans-synaptic control (Bannerjee et al., 1992).

Experiments in $\mathrm{TH}^{+}$cell lines have elucidated enhancer elements homologous to consensus binding sites for known transcription factors and have facilitated the identification of proteins that bind important sites (Yoon and Chikaraishi, 1994). Mutational analyses demonstrate that different enhancers are important in different cell lines. In CATH.a and CATH.b (CNS lines) and PC12, SK-N-BE(2)C, and PATH.2 (PNS lines), the cAMP response element (CRE) at -45 base pairs (bp) is essential for basal transcription as well as cAMP-induced transcription (Kim et al., 1993a,b; Lazaroff et al., 1995). However, in two subclones of the PC12 line the CRE plays a less important role. In PC8b cells the major enhancer consists of an activator protein 1 (AP1) site at $-205 \mathrm{bp}$ and an overlapping site with dyad symmetry (dyad), the core of which is an E box (Yoon and Chikaraishi, 1992). In a different PC12 line, a region around -578 to -503 bp confers transcriptional activity (Wong et al., 1994). In PC8b cells the AP1 site also can partially sustain cAMP induction (Fung et al., 1992), whereas the dyad/E box seems to confer cell type specificity on the TH promoter (Yoon and Chikaraishi, 1992). In PC12 cells the AP1 and CRE sites also can mediate induction of TH transcription by nerve growth factor (Gizang-Ginsberg and Ziff, 1990; Ghee et al., 1994) and depolarization (Kilbourne et al., 1992; Nagamoto-Combs et al., 1997). Thus, the AP1 and CRE motifs are the major enhancers for most basal and induced transcription of TH.

Upstream enhancer elements usually work in an orientation and distance-independent manner. In contrast, the basal promoter region, which encompasses the TATA box through the start site of transcription $(+1)$, binds RNA polymerase II and basal transcription factors in an orientation and distance-dependent manner but cannot activate transcription without the aid of upstream enhancers. For most genes basal promoters are thought to 

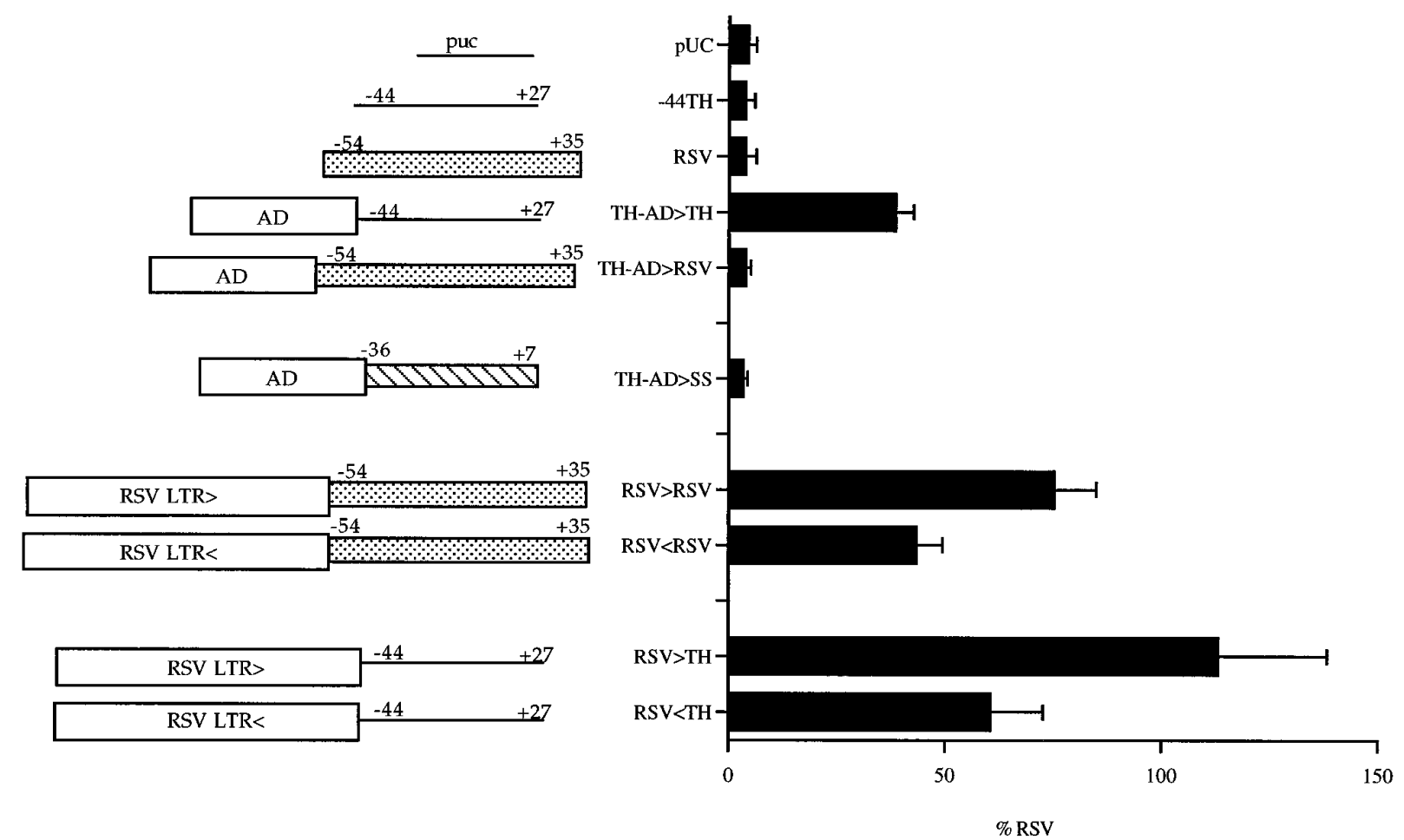

Figure 1. Analysis of the TH, somatostatin, or RSV basal promoters with RSV or TH enhancers in PC8b cells. Lines represent either pUC or TH promoter sequences; stippled boxes represent RSV promoter sequences; hatched box represents rat somatostatin promoter sequence; open boxes represent either TH or RSV enhancer elements. The orientation of the RSV enhancer is denoted by $>$ and $<$. Each schematic representation of a construct is aligned next to the appropriate bar on the histogram. That the RSV-RSV constructs gave $\sim 50-75 \%$ of the activity of the positive control, RSVCAT, to which all other constructs are compared, reflects differences in the sequences of the two RSV enhancers that were derived from different strains of virus. Normalized CAT values for positive control RSVCAT activities are, for PC8b cells in three individual experiments, 18.3 , SD $=2.5(n=6)$; in three other experiments, $4.3, \mathrm{SD}=8(n=6)$.

be functionally interchangeable, with the TATA box region serving as the only sequence-specific binding site necessary for assembling the basal transcription machinery.

The TH gene is unusual in that its upstream enhancers are unable to transactivate a basal promoter from a heterologous gene. We identify here the promoter element, which we call the partial dyad, responsible for this specificity. It lies between the TH TATA box and transcriptional initiation site. When it is introduced into a heterologous promoter, the partial dyad restores transcriptional activity. We show that the partial dyad is important in all cell lines tested, regardless of whether the AP1 or CRE enhancer predominates or whether they express TH. However, the partial dyad is not required for cAMP- or depolarizationinduced expression. In conclusion, we have identified a novel element in the $\mathrm{TH}$ promoter that may be bound by proteins at the basal transcription complex that specifically mediate activation by TH enhancer elements.

\section{MATERIALS AND METHODS}

Cell culture. The rat pheochromocytoma cell line, $\mathrm{PC} 8 \mathrm{~b}$, is a subclone of the PC12 cell line (Tank et al., 1990). The rat B103 cell line was derived from CNS tumors induced in rats by nitrosoethylurea. B103 cells display some neuronal properties and are TH-negative (Schubert et al., 1974). HeLa (human) and NIH3T3 (mouse) were obtained from American Type Tissue Culture collection (Rockville, MD); Fr3T3 (rat fibroblasts analogous to mouse NIH3T3) have been described previously (Seif and Cuzin, 1977) and were generously supplied by Dr. Carlos Sonenshein, Tufts University Medical School. The CATH.a, CATH.b, and PATH.2 cells were derived from CNS and adrenal tumors that developed in transgenic mice expressing SV40 T-antigen under the transcriptional control of 0.8 $\mathrm{kb}$ of rat TH $5^{\prime}$ flanking sequences (Suri et al., 1993). The CAD cells are a variant of CATH.a that can undergo morphological differentiation (Qi et al., 1997).

PC8b, B103, CATH.a, CATH.b, and PATH.2 cells were maintained as described previously (Yoon and Chikaraishi, 1992; Lazaroff et al., 1995). SK-N-BE(2)C and PC12 cells were maintained as previously described (Kim et al., 1993a), except that sera were not heat-inactivated. CAD cells were maintained in DMEM/F12 with $10 \%$ fetal calf serum. NIH3T3 and HeLa cells were grown in DMEM with $10 \%$ fetal calf serum. Fr3T3 cells were grown in DMEM with $10 \%$ iron-supplemented calf serum. All media contained $100 \mathrm{U} / \mathrm{ml}$ of penicillin and $100 \mu \mathrm{g} / \mathrm{ml}$ of streptomycin.

Construction of plasmids. The $-272 \mathrm{THCAT},-272 \mathrm{CRE}^{-},-38 \mathrm{TH}-$ CAT, -44THCAT, and RSVDE constructs have been described previously (Fung et al., 1992; Yoon and Chikaraishi, 1992; Lazaroff et al., 1995). The $\mathrm{AD}(-229 /-160 \mathrm{bp})-\mathrm{TH}$ and $\mathrm{AD}(-229 /-160 \mathrm{bp})-\mathrm{RSV}$ constructs are identical to the 70 mer-TH and 70 mer-RSV constructs in Fung et al. (1992).

The RSV enhancer from the Rous sarcoma virus [strain SR-A(SF)] was amplified by PCR, using the primers indicated below; the resulting fragment was cloned into the TA cloning vector pCRII (Invitrogen, San Diego, CA). The RSV enhancer subsequently was cloned in both orientations into the $-44 \mathrm{TH}$ and RSV $\Delta \mathrm{E}$ constructs at the SacI sites of their polylinkers: RSV LTR (sense), 5'GATTGAGCTCGGCAGGCAAGACAGCTATTTG3'; RSV LTR (antisense), 5'GATTCAGCTGAATTCAGTGGTTCGTCCAATCC 3 '.

The $\operatorname{AD}(-229 /-160$ bp)-SS construct was created in two steps. First, a NcoI/SalI fragment consisting of a polylinker (SalI, PstI, HindIII) and $\mathrm{N}$-terminal sequences from the CAT gene from - 71 SS-CAT (Montminy et al., 1986) was cloned into the unique NcoI/SalI sites of the $\operatorname{AD}(-229 /$ $-160 \mathrm{bp})$-TH plasmid. This resulted in the TH AD enhancer driving a promoterless CAT reporter. Oligonucleotides encompassing the entire somatostatin basal promoter from -43 bp to +7 (Montminy et al., 1984) then were cloned into the unique SalI site, resulting in the $\mathrm{AD}(-229 /$ $-160 \mathrm{bp}$ ) > SS construct: SS oligonucleotide (sense), 5'TCGAGAGTATAAAAAGGGGAGACCGTGGAGAGCTCGATAGCGGC3'; SS 
A
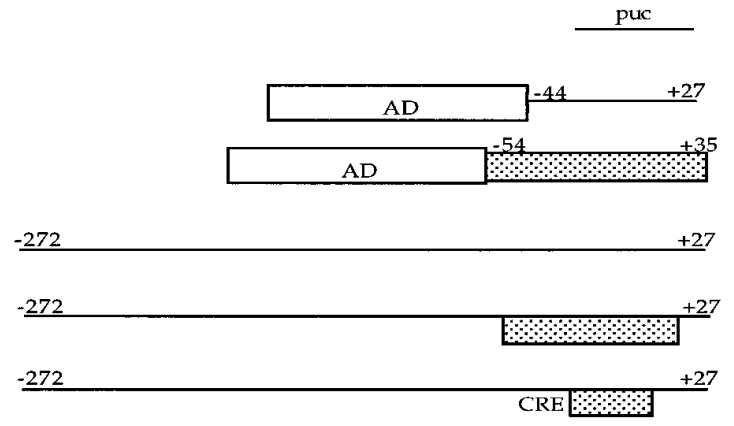

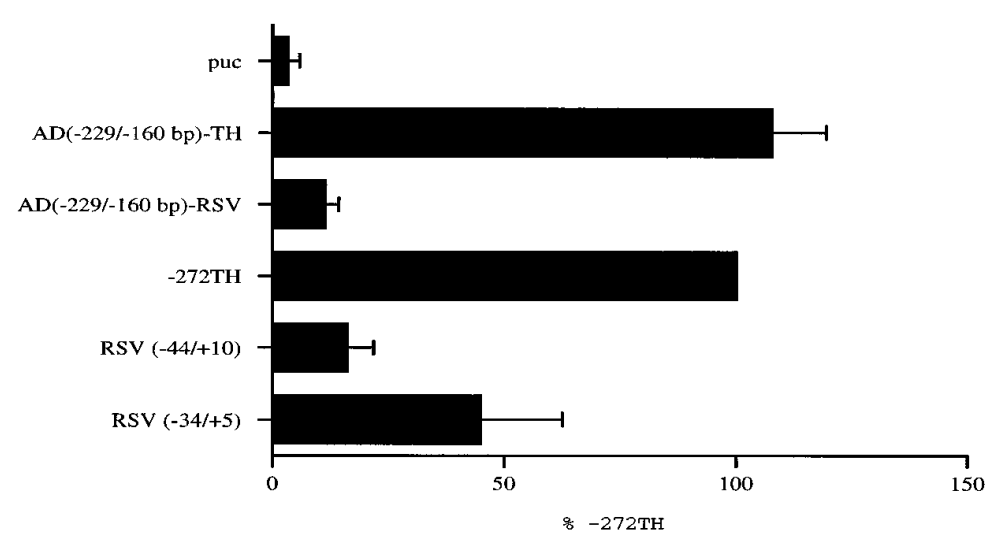

B

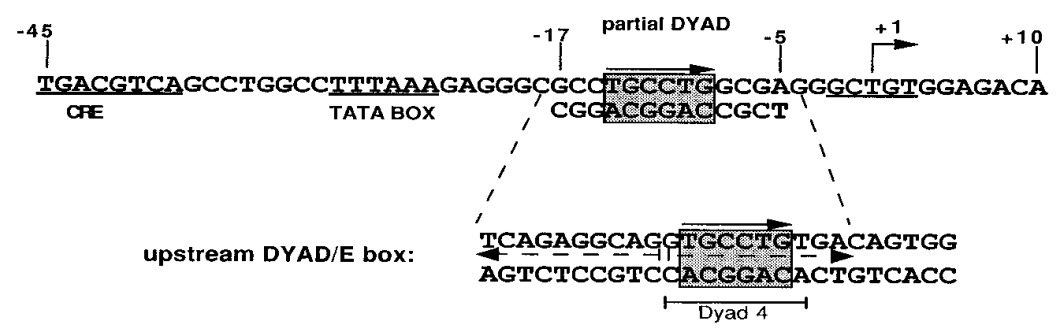

C
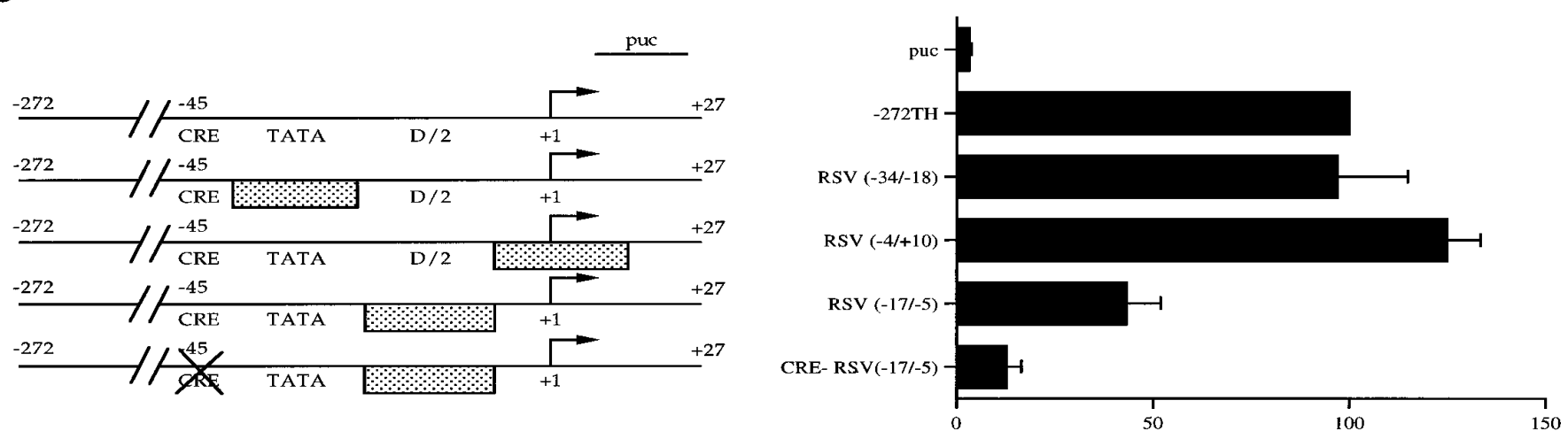

D

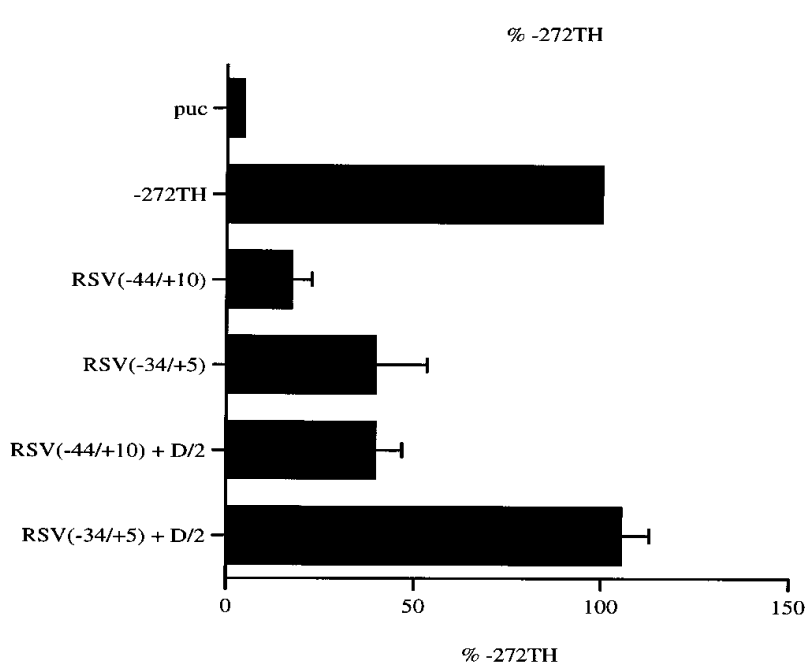

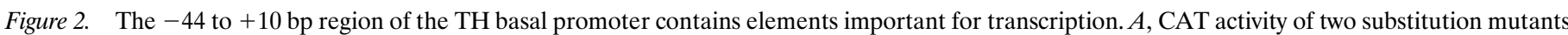

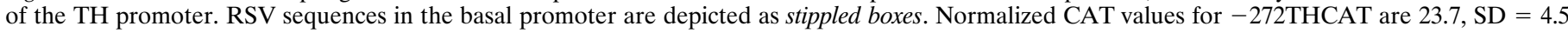

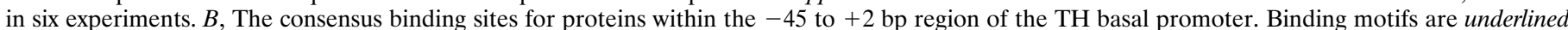

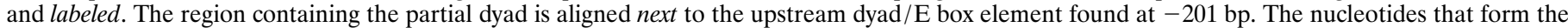

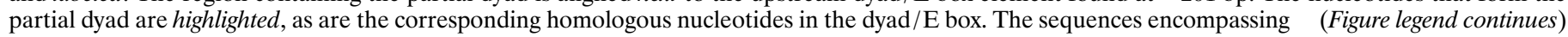


oligonucleotide (antisense), 5'TCGAGCCGCTATCGAGCTCTCCACGGTCTCCCCTTTTTAAACTC3'.

The TATA box mutant $[-272 \operatorname{RSV}(-34 /-18)]$ was generated by site-directed mutagenesis as described in Yoon and Chikaraishi (1992), using the following oligonucleotide: 5'CTCCACAGCCCTCGCCAGGCAGGCggcacttaaatacaataGGCTGACGTCAAAGCCCCTCTGGG3'. Nucleotides shown in upper case are TH sequences, whereas nucleotides shown in lower case are RSV sequences.

All mutations in the promoter of -272THCAT were made by a PCR-based site-directed mutagenesis that used two unique AvaI sites at -210 and +14 bp. PCR was performed with two primers, one of which was perfectly complementary at the $-210 \mathrm{bp}$ position (upstream $-210 \mathrm{bp}$ sense oligonucleotide), whereas the other carried mutations within the $\mathrm{TH}$ sequences but retained $\mathrm{TH}$ sequences around the +14 bp position.

Oligonucleotides used for mutagenesis included upstream $-210 \mathrm{bp}$ oligonucleotide (sense), 5'CGTGCCTCGGGCTGA3'; RSV(-44/+10) oligonucleotide (antisense), 5'TGGTGGTCCCGAGTTCgtaaaatggcgtttattgtatcgagctaggcacttaaatacaatatctctgcgaAAAGCCCCTCTGGGTC3'; $\mathrm{RSV}(-34 /+5)$ oligonucleotide (antisense), 5'TGGTGGTCCCGAGTTCTGTCTtggcgtttattgtatcgagctaggcacttaaatacaat3'; RSV(-17/-5) oligonucleotide (antisense), 5'CTGGTGGTCCCGAGTTCTGTCTCCACAGCCCattgtatcgagctGCCCTCTTTAAAGGCC3'; RSV(-4/+10) oligonucleotide (antisense), 5'CTGGTGGTCCCGAGTTCgtaaaatggcgttTCGCCAGGCAGGCGCCC3'; RSV $(-44 /+10)$ + D/2 oligonucleotide (antisense), 5'CTGGTGGTCCCGAGTTCgtaaaatggegtttTCGCCAGCAGGCaggcacttaaatacaat3'; RSV $(-34 /+5)+\mathrm{D} / 2$ oligonucleotide (antisense), 5'CTGGTGGTCCCGAGTTCTGTCTtggcgtttTCGCCAGGCAGGCaggcacttaaatacaat $3^{\prime}$.

The following templates were used for PCR amplification. The $\operatorname{RSV}(-34 /+5)$ primer was used with the $-272 \operatorname{RSV}(-34 /-18)$ plasmid as a template, thus extending the RSV sequences another 23 bases. The $\operatorname{RSV}(-44 /+10)$ primer was used with the $-272 \mathrm{RSV}(-34 /+5)$ plasmid as template, thus extending the RSV sequences another 15 bases on either side. For the RSV $(-17 /-5)$ and $\operatorname{RSV}(-4 /+10)$ primers, PCR was performed with either $-272 \mathrm{THCAT}$ or $-272 \mathrm{CRE}^{-}$as template. For the $\operatorname{RSV}(-44 /+10)+\mathrm{D} / 2$ and $\operatorname{RSV}(-34 /+5)+\mathrm{D} / 2$ primers, the $\operatorname{RSV}(-44 /$ $+10)$ and $\operatorname{RSV}(-34 /+5)$ constructs were used as templates. All of the resulting PCR products were digested with $A v a \mathrm{I}$ and recloned into AvaI-digested -272THCAT.

Point mutations in the partial dyad were made by the same PCR strategy described above, using a doped antisense oligonucleotide $(\mathrm{Ge}$ nosys Biotechnologies, The Woodlands, TX). The lower case nucleotides in the doped oligonucleotide were doped at a $10 \%$ frequency: doped oligonucleotide (antisense), 5'CTGGTGGTCCCGAGTTCTGTCTCCACAGCCCtcgccaggcaggcGCCCTC 3'.

All constructs were sequenced to verify the altered sequences.

Transfections and CAT assays. DNA used for transfection was prepared with Qiagen (Hilden, Germany) DNA purification columns. The cell lines were transfected according to the protocols described in previous studies: for PC8b and B103, Yoon and Chikaraishi (1992); for CAD, CATH.a, CATH.b, and PATH.2, Lazaroff et al. (1995); for SK-N-BE(2)C and PC12, Kim et al. (1993a); for Fr3T3, Cambi et al. (1989). HeLa cells were transfected with $10 \mu \mathrm{g}$ of the CAT plasmids and $5 \mu \mathrm{g}$ of SV2gal plasmid per plate. NIH3T3 cells were transfected with $5 \mu \mathrm{g}$ of CAT plasmid, $5 \mu \mathrm{g}$ of SV2gal, and $10 \mu \mathrm{g}$ of PGEM (carrier DNA) per plate. For cAMP induction, PC8b cells were treated with $10 \mu \mathrm{M}$ forskolin (Calbiochem, La Jolla, CA), and CATH.a cells were treated with $1 \mathrm{mM}$ dibutyryl-cAMP (Sigma, St. Louis, MO) $24 \mathrm{hr}$ before harvesting. For $\mathrm{KCl}$ induction, CATH.a cells were treated with $80 \mathrm{~mm} \mathrm{KCl}$ for $12-15 \mathrm{hr}$ in DMEM/F12 medium supplemented with $\mathrm{CaCl}_{2}$ to a final concentration of $6 \mathrm{~mm}$. CAT assays and $\beta$-galactosidase assays were performed according to the previously described protocols for each cell line. The values for normalized CAT activity correspond to multiple samples $(n>4)$. For each construct at least two DNA preparations were used for transfection.

CAT activity was determined by using the following formula: normalized conversion/100 micrograms protein was calculated as the percentage of conversion/hour expressed per $\beta$-gal OD420/hr. Normalized conversion for each construct was expressed as a percentage of the RSVCAT or -272 THCAT value. The absolute percentage of conversion for RSVCAT and -272 THCAT were in the linear range for all experiments. However, the values of normalized conversion differed among experiments, presumably because of slightly different transfection efficiencies that cannot be controlled. Nevertheless, the final values for each construct, when expressed as a percentage of RSVCAT or a percentage of -272THCAT, were always highly reproducible.

\section{RESULTS}

\section{TH promoter elements facilitate TH enhancer activity}

A 70 bp enhancer (-229/-160) from the rat TH gene, encompassing the TH AP1 (A) and dyad/E box (D) elements, activates the TH basal promoter but not the RSV basal promoter in PC8b cells, a subclone of PC12 (Fig. 1). To determine if the difference in promoter efficiency was intrinsic in the promoters themselves, we cloned another enhancer, the ubiquitously acting RSV LTR, upstream of both promoters. Figure 1 shows that both the TH and RSV promoters supported robust expression from the RSV enhancer. These data show that both promoters are fully competent to mediate activation by a strong ubiquitous enhancer, implying that there is no intrinsic deficit in the RSV promoter construct. Nevertheless, they differ dramatically in their ability to work with the TH AD enhancer: the TH basal promoter gives seven times higher CAT activity than the RSV basal promoter when driven by the TH AD enhancer. This suggests that the TH promoter facilitates activation by its own enhancer, which intrinsically may be weak in the absence of proper promoter elements. To confirm this result, we examined the ability of the TH AD enhancer to transactivate another cellular basal promoter, that of the rat somatostatin gene. Figure $1(\mathrm{TH}-\mathrm{AD}>\mathrm{SS})$ shows that the AD enhancer is unable to activate the somatostatin basal promoter as well. Hence, the TH AP1-dyad enhancer and the TH promoter region cooperate to activate transcription in $\mathrm{PC} 8 \mathrm{~b}$ cells.

\section{Mapping of TH promoter elements in PC8b cells}

The constructs used in Figure 1 lacked endogenous TH sequences between -44 and -160 bases and, as a consequence, positioned the $\mathrm{TH} \mathrm{AD}$ region closer to the promoter than normal. To address whether the synergy between the $\mathrm{TH}$ enhancer and its promoter occurred with an intact $5^{\prime}$ region, we replicated the initial observation by using a -272 THCAT construct, which contains contiguous 5 ' sequences between -272 and +27 . Expression from the wild-type -272THCAT construct was compared with that from a construct $(\mathrm{RSV}-44 /+10)$ in which the TH promoter region $(-44$ to $+10 \mathrm{bp}$ ) was replaced with the corresponding RSV promoter sequences. The RSV $(-44 /+10)$ substitution showed an $85 \%$ decrease in CAT activity when compared with the wild-type $-272 \mathrm{TH}$ construct (Fig. $2 A$ ). In the same experiment a similar low level of CAT activity was observed with the $70 \mathrm{bp}$ AD enhancer driving the RSV promoter. Thus, we conclude that in PC8b cells basal promoter elements that support activity of the TH AP1-dyad enhancer function in the context of the intact 5' region and lie between -44 and +10 .

The -44 to +10 region contains four potential elements im-

the Dyad 4 mutation (Yoon and Chikaraishi, 1992) are underlined and labeled. $C$, CAT activity of the CRE, the TATA box, the partial dyad, and the +1 region mutants in PC8b cells. Lines are TH sequences, and stippled boxes are RSV sequences. The crossed CRE denotes the substitution of the CRE with an XhoI restriction site. The upstream TH sequences from -45 to -272 bp are intact. Normalized CAT conversion values for $-272 \mathrm{THCAT}$ are 40.8 , $\mathrm{SD}=13.7(n=10) . D$, CAT activity of constructs that replace the partial dyad in the two substitution mutants depicted in $A$. Normalized CAT conversion values for -272 THCAT are $1.0, \mathrm{SD}=0.2(n=4)$ and $52.4, \mathrm{SD}=1.8(n=2)$. Bars with no apparent error bars had SD less than could be depicted graphically in this figure and subsequent figures. 
portant for transcription (shown in Fig. 2B): (1) the CRE site at $-45 /-38 \mathrm{bp}$; (2) the TATA box (-29/-24 bp); (3) a partial or half dyad region $(-17 /-5 \mathrm{bp})$, consisting of the sequence $5^{\prime}$ GCCTGCCTGGCGA 3' that shows homology to the dyad symmetry element at -201 to $-182 \mathrm{bp}$; and (4) the region surrounding the transcriptional start site at +1 . The -44 to +10 substitution mutant lacked all four elements.

To map specific elements in the -44 to +10 region, we substituted the sequences between -34 and +5 bp with the corresponding RSV promoter sequences. This construct (RSV -34/+5) retained a complete $\mathrm{CRE}$ and reduced expression to $50 \%$, as compared with an $85 \%$ reduction observed when the CRE was absent (Fig. 2A). This suggests that approximately one-half of the $\mathrm{TH}$ promoter activity maps to the CRE. We have determined previously that the CRE behaves as a weak enhancer in PC8b cells, because a minimal enhancer construct consisting of the CRE driving a TH basal promoter gives low levels of CAT activity (data not shown).

Because the RSV promoter $(-34$ to +5$)$ supported only onehalf of the activity of the TH promoter (Fig. $2 A$ ), we tested the importance of the other individual elements in the -34 to +5 region. The TH TATA box was changed to that of RSV. Surprisingly, this construct (RSV-34/-18) showed no reduction in CAT activity, as compared with the -272THCAT construct (Fig. 2C), indicating that the important $\mathrm{TH}$ promoter elements lie downstream of the TATA box. A $\beta$-globin TATA box also supported $100 \%$ expression (data not shown), suggesting that the TH enhancer may be relatively indiscriminate with regard to the TATA box with which it can work. This result was unexpected, because many of the specialized promoter sequences mapped in other genes have centered on the TATA box (McCormick et al., 1991; Desmarais et al., 1992; Fong and Emerson, 1992; Barton et al., 1993). The -34 to +5 region also contains the nucleotides surrounding the transcriptional initiation site of $\mathrm{TH}(+1$ site). When this region was substituted with the RSV +1 region $(\mathrm{RSV}-4 /+10)$, full activity was obtained, suggesting that in the TH promoter the transcriptional start site does not interact specifically with $\mathrm{TH}$ upstream enhancers.

In contrast, when the partial dyad region $(-17 /-5)$ of $\mathrm{TH}$ was replaced with the analogous RSV sequences, CAT levels were reduced to $45 \%$ of wild type (Fig. $2 C$ ). Hence, the partial dyad region seems to be the functional promoter element required in PC8b cells. Although substitutions at either the CRE or the partial dyad individually reduced expression by $\sim 45-50 \%$, a substitution that included both elements (RSV $(-44 /+10)$ in Fig. $2 A)$ reduced expression by $85 \%$, suggesting that the effect of the two elements was equal and additive. To test this directly, we changed both elements such that the CRE was mutated and RSV sequences replaced those of the partial dyad site; TH sequences were retained at the TATA box and over the +1 site. This construct $\left(\mathrm{CRE}^{-} \mathrm{RSV}-17 /-5\right)$ supported only $11 \%$ of wild-type activity, demonstrating that, indeed, in PC8b cells the important elements within the -44 to +10 region of $\mathrm{TH}$ are the CRE and partial dyad.

Having mapped the partial dyad as an essential element by mutational analysis in PC8b cells, we tested whether replacement of this element into the partially active $\operatorname{RSV}(-34 /+5)$ and the inactive $\operatorname{RSV}(-44 /+10)$ constructs would restore transcriptional activity. These "gain of function" constructs are shown in Figure $2 D$. As expected, the presence of a partial dyad in the RSV $(-44 /$ $+10)$ construct that lacks both the partial dyad and CRE increases CAT activity to $50 \%$ [construct, $\operatorname{RSV}(-44 /+10)+\mathrm{D} / 2$ ]. Simi- larly, inclusion of the partial dyad in the RSV $(-34 /+5)$ construct that lacks the partial dyad but retains the CRE restores transcriptional activity to levels equal to or better than wild-type $[\mathrm{RSV}(-34 /+5)+\mathrm{D} / 2]$. Thus, by both mutation and replacement studies, the partial dyad in the basal promoter is necessary for AD enhancer function in PC8b cells.

\section{The partial dyad element is required in all $\mathrm{TH}-$ expressing and TH-negative cell lines tested}

To assess the role of the partial dyad in other $\mathrm{TH}^{+}$cell lines, we transfected the partial dyad mutant into six other catecholaminergic cell lines. These included mouse lines (CATH.a, CATH.b, and PATH.2), rat PC12 cells, and a human neuroblastoma [SK$\mathrm{N}-\mathrm{BE}(2) \mathrm{C}$. Unlike PC8b cells, which rely on the AD enhancer for basal expression, these cell lines use the TH CRE site as the predominant enhancer (Kim et al., 1993a; Lazaroff et al., 1995). We included an additional cell line, CAD, which exhibits a third transcriptional pattern in which the AP1 and CRE motifs are of equal importance (M. Lazaroff and D. M. Chikaraishi, unpublished data). Figure $3 A$ shows that the partial dyad mutation (RSV-17/-5) resulted in a reduction of CAT activity to $22-35 \%$ of the wild-type levels in the CATH.a, CATH.b, PATH.2, and PC12 cell lines and a reduction of CAT activity to $45 \%$ in the SK-N-BE(2)C and the CAD cells. Thus, the partial dyad is required for full expression in seven different TH-positive cell lines regardless of which enhancer directs basal $\mathrm{TH}$ expression. In all lines the -44THCAT construct that contains promoter sequences, including the partial dyad, gives low levels of CAT activity, indicating that the partial dyad cannot sustain transcription in the absence of upstream enhancers.

Next, the role of the partial dyad in TH-negative lines was investigated. In general, absolute levels of CAT activity driven by the -272 THCAT construct are much lower in TH-negative lines; nevertheless, it was still possible to test whether this low level of expression was dependent on the partial dyad. In four $\mathrm{TH}-$ negative lines (HeLa, Fr3T3, NIH3T3, and B103), the RSV(-17/ $-5)$ construct gave transcriptional activity between 30 and $75 \%$ of the wild-type construct (Fig. $3 B$ ). Hence, the partial dyad is required for efficient transcription in all cell lines studied, irrespective of whether they express $\mathrm{TH}$; this suggests that the partial dyad does not confer cell line-specific expression. The partial dyad mutation had a smaller effect in both human cell lines [SK-N$\mathrm{BE}(2) \mathrm{C}$ among the TH-expressing and HeLa among the nonexpressing lines], as compared with the rodent lines, perhaps reflecting some species specificity.

\section{Mutational analysis of the partial dyad}

To characterize the partial dyad further, we performed limited mutational analysis of the $-17 /-5$ region; these mutations are described in Figure 4. All mutations were made in the context of the -272 THCAT plasmid and tested for transcriptional activity in both the CATH.a and PC8b cell lines. The mutations fell into three categories. Mutants 1 and 2 had no effect on activity. The fact that mutant 2 was not deleterious was surprising because it was a triple mutation with substitutions at positions $-16,-15$, and -14 . Two mutants (3 and 5) modestly reduced activity, whereas mutant 4 , in which $\mathrm{G}$ at -17 was changed to $\mathrm{C}$ and $\mathrm{C}$ at -11 was changed to $\mathrm{A}$, dramatically reduced activity to a greater extent than that of the full substitution mutant, $\operatorname{RSV}(-17 /-5)$. This double mutant reduced CAT levels by $80 \%$ in both cell lines. To assess the contribution of each of the mutant sites individually, we tested single substitutions. These single substitutions (mutants 
A
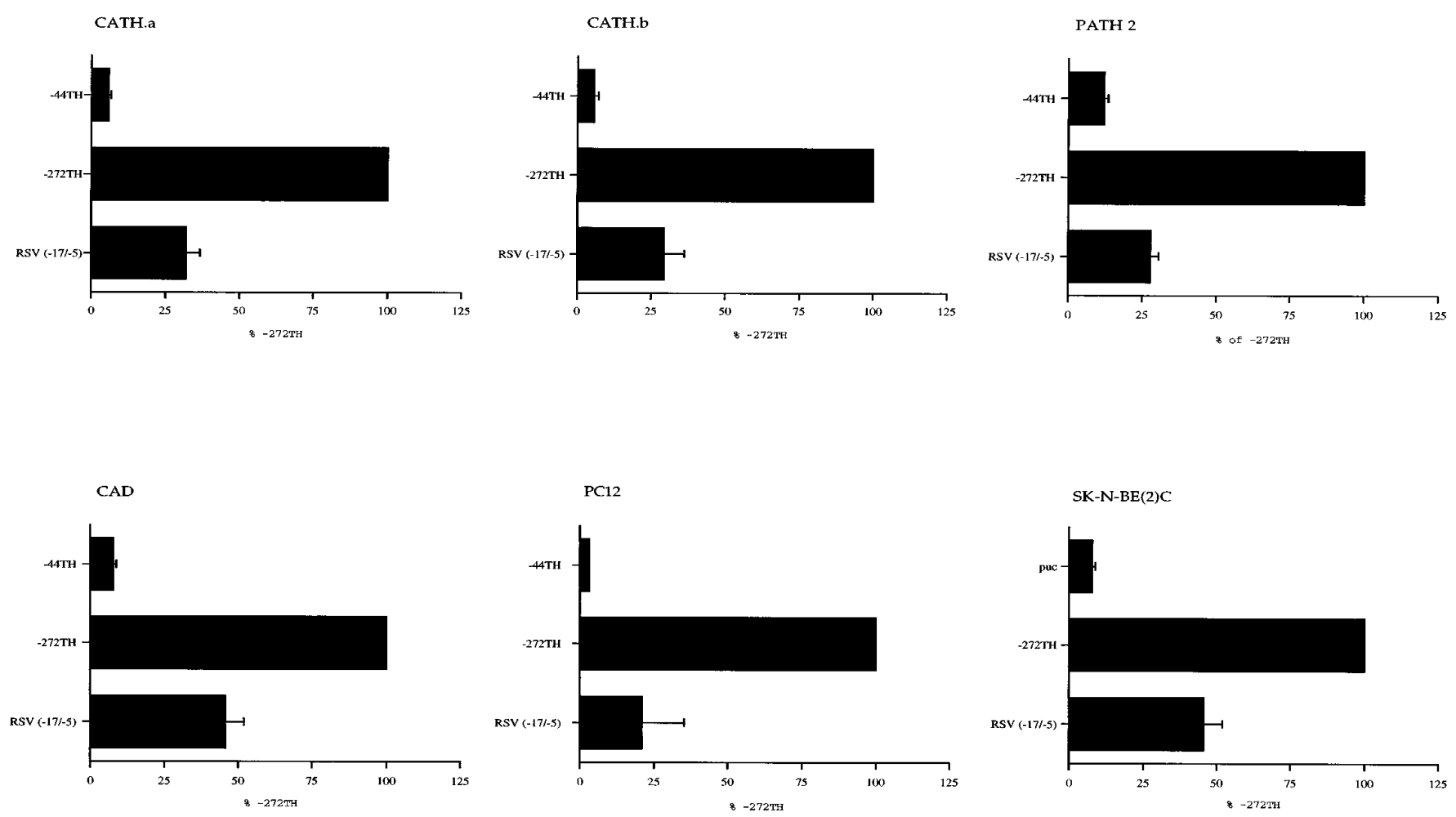

B
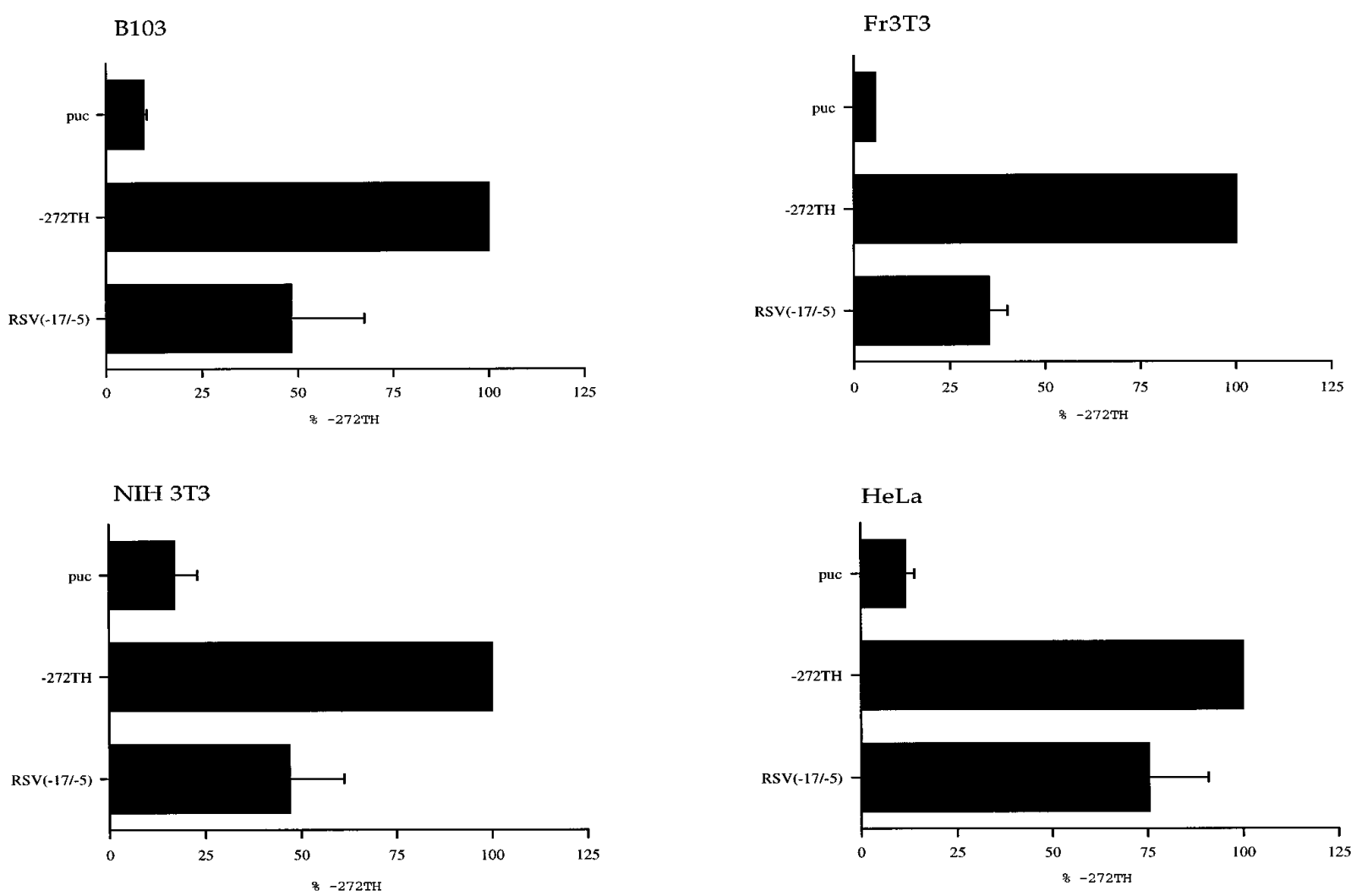

Figure 3. $A$, The partial dyad element is required for TH transcription in many TH-expressing cell lines. Note that the data are represented as a percentage of -272 THCAT. Normalized CAT conversion values of $-272 \mathrm{THCAT}$ to which all other values were compared are $C A T H . a, 125.9$, SD $=5.3$; $C A T H . b, 6.0, \mathrm{SD}=2.0 ; P A T H .2,5.4, \mathrm{SD}=1.2 ; S K-N-B E(2) C, 149.0, \mathrm{SD}=8.0 ; P C 12,3.0, \mathrm{SD}=1.0 ;$ and $C A D, 961.7, \mathrm{SD}=54.5$ and $308.6, \mathrm{SD}=40.4$ in two separate experiments. $B$, The partial dyad is required for full expression in TH-negative lines. Normalized CAT conversion values of $-272 \mathrm{THCAT}$ to which all other values were compared are $B 103,0.8, \mathrm{SD}=0.2 ; \mathrm{Fr} 3 T 3,42.5, \mathrm{SD}=4.3 ; \mathrm{NIH} 3 \mathrm{T3}, 1.7, \mathrm{SD}=0.5 ;$ and $\mathrm{HeL} a, 42.6, \mathrm{SD}=4.5$. 
PARTIAL DYAD SEQUENCE
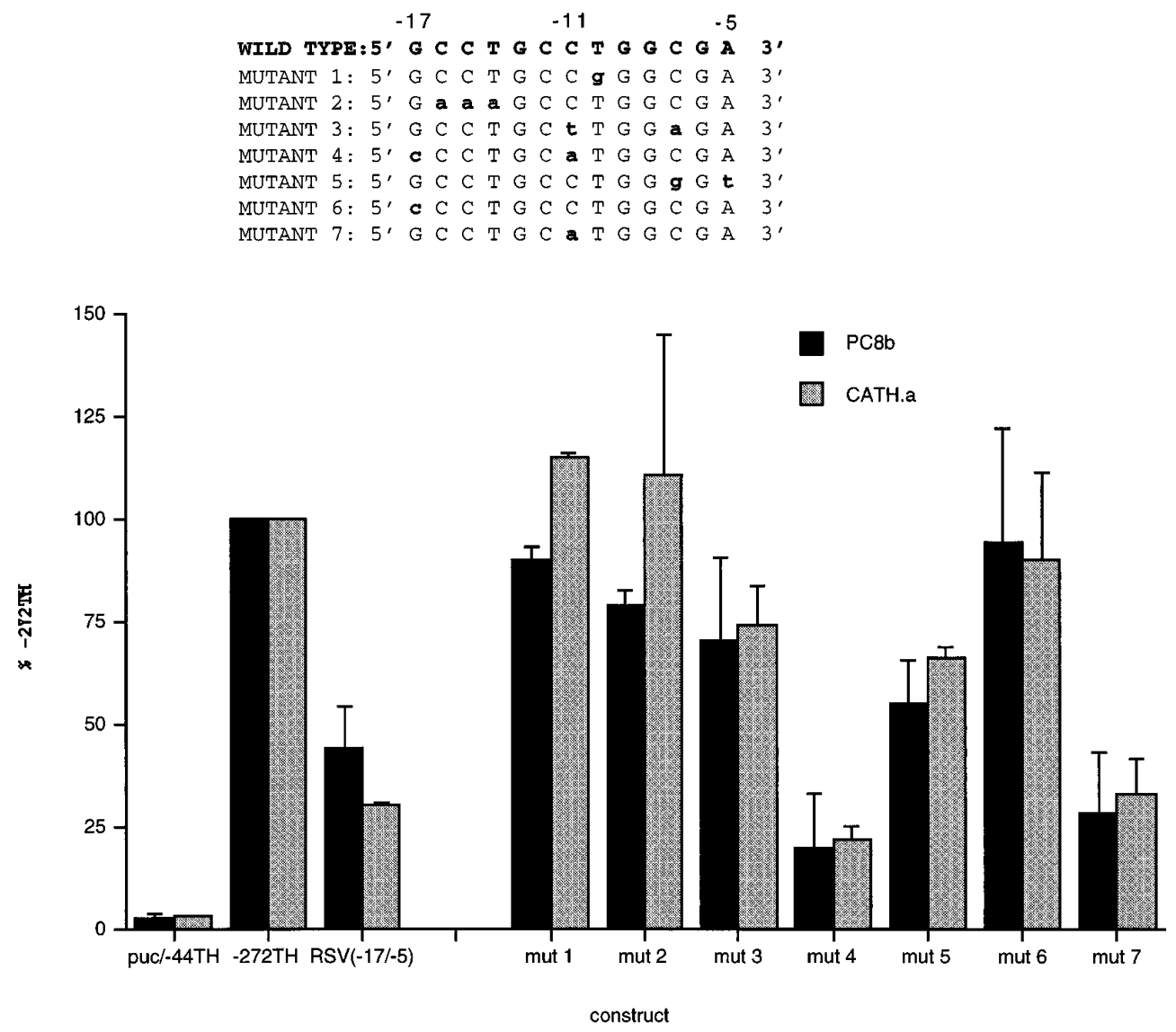

Figure 4. Top panel, Description of the point mutants of the partial dyad. Bottom panel, CAT activity of each mutant in PC8b and CATH.a cells. Normalized CAT conversion value of -272THCAT in the PC8b cells is 17.0, $\mathrm{SD}=4.5(n=6)$ and 5.6, $\mathrm{SD}=1.7(n=4)$ in five separate experiments. Normalized CAT conversion value of -272 THCAT in CATH. $a$ is 70.2 , SD $=19.5$.

6 and 7) indicated that the $\mathrm{C}$ at position -11 is a critical base in the partial dyad. Interestingly, if the $\mathrm{C}$ at position -11 is changed to a $\mathrm{T}$ (as in mutant 3 ) instead of an A, partial dyad activity is reduced only modestly to $75 \%$ of wild-type levels, suggesting that the substitution of a purine at -11 is particularly detrimental.

In sum, these data suggest that positions $-17,-16,-15$, -14 , and -10 may not be important for partial dyad function. It is somewhat surprising that mutations at -14 and -10 were not detrimental, because those positions reside in the core of the partial dyad. Substitutions at other positions (pyrimidine at -5 and purine at -7 ) modestly may reduce promoter activity, whereas a pyrimidine at position -11 seems to be crucial for partial dyad function. From this mapping of the partial dyad it seems that important nucleotides lie in the -11 to $-5 \mathrm{bp}$ region.

\section{The partial dyad is not required for cAMP or depolarization induction of TH}

We have demonstrated the importance of the partial dyad for AP1-dyad and CRE-driven transcription of TH under basal conditions. However, the AP1 and CRE enhancers also have been implicated in induced expression of TH. For example, in PC8b both the AP1 and CRE motifs can be induced individually by
cAMP (Fung et al., 1992), whereas in CATH.a the CRE is the sole element that contributes to induction (Lazaroff et al., 1995). Similarly, both AP1 and CRE sites have been implicated in depolarization induction (Nagamoto-Combs et al., 1997), although other studies have implicated only the CRE (Kilbourne et al., 1992) or the AP1-containing region (Stachowiak et al., 1994). Thus, the role of the partial dyad in cAMP and $\mathrm{KCl}$ induction of TH was investigated. In both PC8b and CATH.a cells the -272 THCAT constructs are induced by approximately twofold in the presence of increased levels of cAMP (Fig. 5). In marked contrast to the absolute requirement for the partial dyad in basal transcription of $\mathrm{TH}$, the partial dyad mutant $[\operatorname{RSV}(-17 /-5)]$ was induced efficiently by cAMP. Indeed, the RSV $(-17 /-5)$ construct showed 2.6- to 4.4-fold induction, as compared with the more modest 1.5 - to 2.5 -fold induction seen with the wild-type construct (Fig. 5A,B). Thus, the partial dyad is not required for cAMP induction of $\mathrm{TH}$ and may, in fact, interfere with efficient induction. Because the $\mathrm{PC} 8 \mathrm{~b}$ cells do not respond to $\mathrm{KCl}$ induction, the role of the partial dyad in $\mathrm{KCl}$ induction was tested only in CATH.a cells. $\mathrm{KCl}$ induced expression of the wild-type $-272 \mathrm{TH}$ CAT approximately fourfold. As with cAMP induction, mutation of the partial dyad did not reduce induction but modestly increased it from fourfold to 5.6-fold (Fig. 5C). Hence, the partial dyad is not required for cAMP or $\mathrm{KCl}$ induction. 

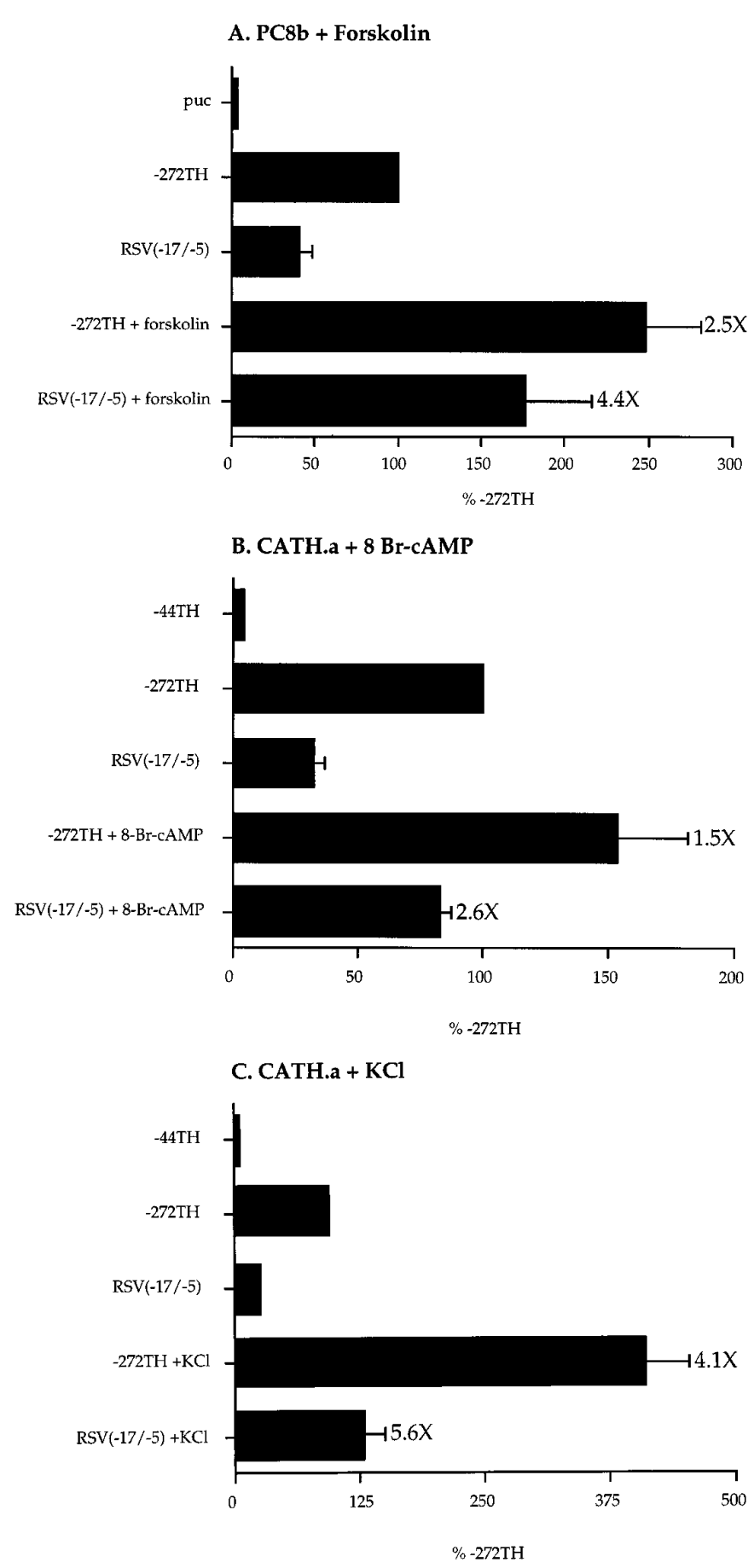

Figure 5. The partial dyad is not required for $(A, B)$ cAMP or $(C) \mathrm{KCl}$ induction of TH in PC8b and CATH.a cells. The fold induction over basal levels is indicated. Normalized conversion for -272 THCAT is $16.1, \mathrm{SD}=$ $2.1(A) ; 125.9, \mathrm{SD}=5.3(B)$; and 153.6, $\mathrm{SD}=32.1(C)$.

\section{DISCUSSION}

Recent studies have shown that the basal promoters of some genes contain unusual elements. Many of these are thought to be important for tissue-specific expression and may work in conjunction with cell-specific enhancers to ensure tight transcriptional regulation. Given that many neuronal genes are highly cellspecific, it is likely that some, like TH, would be activated by specific enhancer-promoter combinations.
Some unusual promoter elements are initiator (Inr) sequences that reside around the +1 site of genes that lack TATA boxes [Bellorini et al. (1996) and references therein; for review, see Weis and Reinberg (1992)]. These initiator elements functionally replace the TATA box and position the basal transcriptional complex at the correct transcriptional start site. However, the identified TATA box in the TH gene at -29 bp seems to be fully functional in that mutations in it reduce transcriptional activity almost to background levels (Yoon and Chikaraishi, 1992) and alter the start site of transcription (data not shown).

Some TATA boxes themselves confer cell type specificity. For example, the TATA box and surrounding regions of the GHF-1 (McCormick et al., 1991) and peripherin (Desmarais et al., 1992) genes are capable of directing cell type-specific expression. In the basal promoters of the genes for human alcohol dehydrogenase, two C/EBP sites located on either side of the TATA box were shown to be critical elements for $\mathrm{C} / \mathrm{EBP}$ transactivation (Stewart et al., 1990a,b). The chick $\beta$-globin genes contain a noncanonical TATA box consisting of a GATA sequence; erythroid-specific expression of the $\beta$-globins is regulated at the GATA site in the basal promoter by the cGATA-1 protein (Fong and Emerson, 1992; Barton et al., 1993). Indeed, the TH TATA box is also a nonclassical sequence (TTTAAA). However, the TH enhancer failed to activate the somatostatin promoter (Fig. 1), which contains the same noncanonical TATA box, suggesting that the ability of the $\mathrm{TH}$ enhancer to activate the $\mathrm{TH}$ promoter specifically is not attributable to its noncanonical TATA box. Moreover, replacing the TH TATA box with either that of the RSV LTR or $\beta$-globin genes did not reduce transcriptional activation, suggesting that the TH TATA box can be replaced functionally by other TATA boxes and, hence, is not unusual. Likewise, replacing the $\mathrm{TH}+1$ region with that of the RSV LTR supported full transcriptional activation, demonstrating that the $\mathrm{TH}$ initiation site can be replaced functionally with that of a heterologous gene.

Therefore, in contrast to many previously identified promoter elements, the sequence unique to the TH promoter that is critical for full transcriptional activity is neither the TATA box nor the initiation site. Our mapping positions the important element between the TATA box and the +1 site. Its core $(-14$ to $-9 \mathrm{bp})$ is homologous to one-half of an upstream dyad symmetry element required for AP1 enhancer activity in PC8b cells; hence, this element is termed partial dyad (Fig. 2B). We show with both mutational (Fig. 2C) and replacement (Fig. 2D) constructs that the partial dyad is necessary for AP1-dyad-driven transcription in PC8b cells and also for CREdriven transcription in CATH.a cells (Fig. $3 A$ ). That the partial dyad is essential for full expression in cell lines that are dependent on different enhancers suggests that, perhaps, the unusual TATA box (TTTAAA) in the basal promoter requires another element to position the basal promoter complex correctly in response to the AP1- and CRE-bound transactivators.

We also show that mutation of the partial dyad at two specific positions $(-17$ and -11$)$ abolishes transcriptional activity in both PC8b and CATH.a cells (Fig. 4). Electrophoretic mobility shift assays (data not shown) were performed to determine if protein complexes bind the partial dyad element. Using PC8b and HeLa nuclear extracts, we observed two weak yet distinct complexes binding to a labeled partial dyad oligonucleotide; one of these complexes was abolished when an oligonucleotide containing mutations at positions -17 and -11 was used. Hence, the partial dyad seems to be bound by sequence-specific binding proteins.

A search of the transcription factor site database failed to show any consensus sequence that matched the partial dyad. Interest- 
rat promoter $(-29 /+1)$ :

rat upstream $(-205 /-182)$ :

mouse promoter $(-27 /+1)$ :

mouse upstream $(-204 /-181)$ :

human promoter $(-30 /+1)$ :

human upstream $(-204 /-186)$ :

bovine promoter $(-29 /+1)$ :

bovine upstream $(-222 /-204)$ :
TATA bOX

5' TTTAAAGAGGGCGCCIFGCCIGGCGAGGGCT 3'

AP 1

5. TGATTCAGAGGCAGGIIGCCIEIGA 3'

3' ACTAAGTCTCCGTCCACGGAOACT 5'

\section{TATA bOX}

5' TTTAAGAGGCCGCGIGCCTEGGCAAGGGC 3'

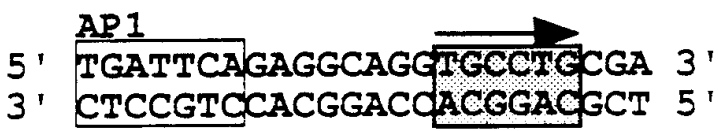

TATA bOX

5' TTATTAGAGGCTECTGGE AAGGGETETGGA 3 '

3. AATAATCTCCGACGACCOC GTCCCGAOACCT 5'

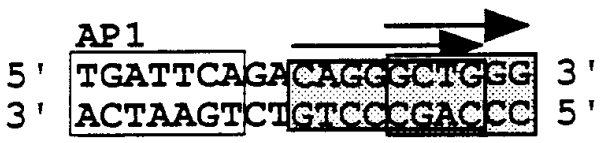

\section{TATA BOX}

5' TATAAAGGCAGCEGGGEA AGGGCTGTGGA 3 '

3' ATATTTCCGTCGECCCGTCICCCGACACCT 5'

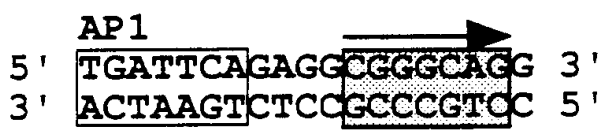

Figure 6. Promoter and upstream sequences of the $5^{\prime}$ flanking regions of rat, mouse, human, and bovine TH genes. The conserved AP1 site and the TATA box of each gene are boxed. The regions of homology between the promoter and upstream sequences of each gene are shown in shaded boxes. Arrows indicate that the regions of homology are present as direct repeats.

ingly, the partial dyad region in all sequenced mammalian $\mathrm{TH}$ genes shows similarity to sequences proximal to the AP1 site at -205 bp (Fig. 6). In the mouse and rat genes the AP1-adjacent sequences form a region of dyad symmetry centered on an $\mathrm{E}$ box (CAXXTG), whereas in the human and bovine genes there is no obvious dyad. Nevertheless, the similarity between the partial dyad region $(-17 /-5)$ and sequences immediately $3^{\prime}$ to the AP1 site is conserved within each species. Hence, although the actual sequences that comprise the partial dyad element differ between species, its identity with the upstream region at -200 is strictly conserved, suggesting that evolutionary pressure has maintained the homology. This similarity between sequences at the basal promoter and those adjacent to the AP1 enhancer suggests that the two sites may be bound by similar proteins, a scenario that might explain the observation that the $\mathrm{AD}$ enhancer and basal promoter cooperate in PC8b cells (see Fig. 1). In the rodent $\mathrm{TH}$ genes (Harrington et al., 1987; Iwata et al., 1992), a direct repeat corresponding to the right arm of the dyad also is present in the basal promoter and is identical in the rat and mouse, whereas in the human (Kobayashi et al., 1988) and bovine (D'Mello et al., 1989) TH genes an identical GC-rich sequence is present at both sites. This divergence might explain why mutation at the rat partial dyad causes a more modest reduction in human cell lines, as compared with rodent lines (see Fig. $3 A, B$ ).

The partial dyad element in the TH basal promoter is necessary for efficient transcription in seven $\mathrm{TH}$-expressing cell lines that we have examined, yet the partial dyad does not seem to mediate cell line-specific expression because it is also necessary for expression in 
TH-negative cell lines. Thus, proteins binding the site may be ubiquitous. The partial dyad is required in TH cell lines that rely on the CRE as well as those that require the AP1-dyad element for enhancer activity. Hence, it seems to mediate a requisite promoter function necessary for both AP1-dyad and CRE-driven expression. In contrast, the RSV enhancer works equally well on the TH and RSV promoters (see Fig. 1), suggesting that the partial dyad may synergize specifically with enhancers found in the TH gene.

In contrast to its essential role in basal transcription, the partial dyad is not required for cAMP or $\mathrm{KCl}$ induction of TH. Transcriptional mechanisms of cAMP induction have been elucidated with the cloning of CREB-binding protein (CBP) (Chrivia et al., 1993), a coactivator that binds serine 133 phosphorylated CREB (Kwok et al., 1994) as well as unphosphorylated c-fos (Bannister and Kouzarides, 1995). In the basal complex CBP can bind RNA polymerase II (Kee et al., 1996) and TFIIB (Kwok et al., 1994). For TH, experiments in PC12 and F9 cells have shown that both the AP1 and CRE sites are required for efficient cAMP induction (Ghee et al., 1995). Thus, CBP may be a bridging protein between AP1- and CRE-bound transcription factors and the basal complex during CAMP induction. We show that, whereas the partial dyad has no essential role in cAMP induction of $\mathrm{TH}$, its presence dampens induction in CATH.a and PC8b cells. This suggests that the modest twofold induction of TH by cAMP could be attributable to the presence of unusual proteins in the basal promoter. Hence, the partial dyad plays an unusual role in basal but not induced transcription of $\mathrm{TH}$.

In conclusion, we have identified a novel element in the $\mathrm{TH}$ basal promoter required for full transcriptional activity in numerous TH-positive and TH-negative cell lines. This element, termed partial dyad, cannot support transcription by itself but increases the efficacy of the TH AP1 or CRE enhancers by three- to fivefold in TH-expressing cells. Mapping of the partial dyad shows that important bases lie between -11 and $-5 \mathrm{bp}$, with a pyrimidine at position -11 being critical for transcriptional activity and formation of an in vitro gel shift complex. The location of the partial dyad in the promoter region between the TATA box and the +1 site and the fact that it cooperates with at least two different enhancer elements suggest that the partial dyad might participate in the assembly or activation of the basal initiation complex. This would put the partial dyad in a unique position to be acted on not only by the CRE and AP1-dyad enhancers but also by other enhancers identified further upstream.

\section{REFERENCES}

Bannerjee SA, Hoppe P, Brilliant M, Chikaraishi DM (1992) 5' flanking sequences of the rat tyrosine hydroxylase gene target accurate tissuespecific, developmental, and trans-synaptic expression in transgenic mice. J Neurosci 12:4460-4467.

Bannerjee SA, Roffler-Tarlov S, Szabo M, Frohman L, Chikaraishi DM (1994) DNA regulatory sequences of the rat tyrosine hydroxylase gene direct correct catecholaminergic cell type specificity of a human growth hormone reporter in CNS of transgenic mice, causing a dwarf phenotype. Mol Brain Res 24:89-106.

Bannister AJ, Kouzarides T (1995) CBP-induced stimulation of c-fos activity is abrogated by E1a. EMBO J 14:4758-4762.

Barton MC, Madani N, Emerson BM (1993) The erythroid protein cGATA-1 functions with a stage-specific factor to activate transcription of chromatin-assembled $\beta$-globin genes. Genes Dev 7:1796-1809.

Bellorini M, Dantonel JC, Yoon J-B, Roeder RG, Tora L, Mantovani R (1996) The major histocompatibility complex class II Ea promoter requires TFIID binding to an initiator sequence. Mol Cell Biol 16:503-512.

Bjorklund A, Lindvall O (1984) Dopamine-containing systems in the CNS. In: Handbook of chemical neuroanatomy, Vol 2, pp 55-122. Amsterdam: Elsevier.
Cambi F, Fung B, Chikaraishi DM (1989) 5' flanking DNA sequences direct cell-specific expression of rat tyrosine hydroxylase. J Neurochem 53:1656-1659.

Chrivia JC, Kwok RPS, Lamb N, Hagiwara M, Montminy MR, Goodman RH (1993) Phosphorylated CREB binds specifically to the nuclear protein CBP. Nature 365:855-859.

Desmarais D, Filion M, Lapointe L, Royal A (1992) Cell-specific transcription of the peripherin gene in neuronal cells involves a cis-acting element surrounding the TATA box. EMBO J 11:2971-2980.

D'Mello SR, Turzai LM, Gioio AE, Kaplan BB (1989) Isolation and structural characterization of the bovine tyrosine hydroxylase gene. J Neurosci Res 23:31-40.

Fong TC, Emerson BM (1992) The erythroid-specific protein cGATA-1 mediates distal enhancer activity through a specialized $\beta$-globin TATA box. Genes Dev 6:521-532.

Fung BP, Yoon SO, Chikaraishi DM (1992) Sequences that direct tyrosine hydroxylase gene expression. J Neurochem 58:2044-2052.

Ghee M, Miller JC, Ziff EB (1994) Regulation of the tyrosine hydroxylase promoter. Soc Neurosci Abstr 20:125.5.

Ghee M, Miller JC, Ziff EB (1995) Regulation of the tyrosine hydroxylase gene requires cooperation between the TH-FSE and CRE. Soc Neurosci Abstr 21:92.

Gizang-Ginsberg E, Ziff EB (1990) Nerve growth factor regulates tyrosine hydroxylase gene transcription through a nucleoprotein complex that contains c-fos. Genes Dev 4:477-491.

Harrington CA, Lewis EJ, Krzemien D, Chikaraishi DM (1987) Identification and cell type-specificity of the tyrosine hydroxylase gene promoter. Nucleic Acids Res 15:2363-2384.

Hynes M, Poulsen K, Tessier-Lavigne M, Rosenthal A (1995) Control of neuronal diversity by the floor plate: contact-mediated induction of midbrain dopaminergic neurons. Cell 80:95-101.

Iwata N, Kobayashi K, Sasaoka T, Hidaka H, Nagatsu T (1992) Structure of the mouse tyrosine hydroxylase gene. Biochem Biophys Res Commun 182:348-354.

Kee BL, Arias J, Montminy MR (1996) Adaptor-mediated recruitment of RNA polymerase II to a signal-dependent activator. J Biol Chem 271:2373-2375.

Kilbourne EJ, Nankova BB, Lewis EJ, McMahon A, Osaka H, Sabban DB, Sabban EL (1992) Regulated expression of the tyrosine hydroxylase gene by membrane depolarization. J Biol Chem 267:7563-7569.

Kim KS, Lee MK, Caroll J, Joh TH (1993a) Both the basal and inducible transcription of the tyrosine hydroxylase gene are dependent upon a cAMP response element. J Biol Chem 268:15689-15695.

Kim KS, Park DH, Wessel TC, Song B, Wagner JA, Joh TH (1993b) A dual role for the cAMP-dependent protein kinase in tyrosine hydroxylase gene expression. Proc Natl Acad Sci USA 90:3471-3475.

Kobayashi K, Kaneda N, Ichinose H, Kishi F, Nakazawa A, Kurosawa Y, Fujita K, Nagatsu T (1988) Structure of the human tyrosine hydroxylase gene: alternative splicing from a single gene accounts for generation of four mRNA types. J Biochem (Tokyo) 103:907-912.

Kobayashi K, Morita S, Sawada H, Mizuguchi T, Yamada K, Nagatsu I, Hata T, Watanabe Y, Fujita K, Nagatsu T (1995) Targeted disruption of the tyrosine hydroxylase locus results in severe catecholamine depletion and perinatal lethality in mice. J Biol Chem 270:27235-27243.

Kwok RPS, Lundblad JR, Chrivia JC, Richards JP, Bachinger HP, Brennan RG, Roberts SGE, Green MR, Goodman RH (1994) Nuclear protein CBP is a coactivator for the transcription factor CREB. Nature 370:223-226.

Lazaroff M, Patankar S, Yoon SO, Chikaraishi DM (1995) The cyclic AMP response element directs tyrosine hydroxylase expression in catecholaminergic central and peripheral nervous system cell lines from transgenic mice. J Biol Chem 270:21579-21589.

McCormick A, Brady H, Fukushima J, Karin M (1991) The pituitaryspecific regulatory gene GHF-1 contains a minimal cell type-specific promoter centered around its TATA box. Genes Dev 5:1490-1503.

Min N, Joh TH, Kim KS, Peng CH, Son JH (1994) 5' upstream DNA sequence of the rat tyrosine hydroxylase gene directs high-level and tissue-specific expression to catecholaminergic neurons in the central nervous system of transgenic mice. Mol Brain Res 27:281-289.

Montminy MR, Goodman RH, Horovitch SJ, Habener JF (1984) Primary structure of the gene encoding rat preprosomatostatin. Proc Natl Acad Sci USA 81:3337-3340.

Montminy, MR, Sevarino KA, Wagner JA, Mandel G, Goodman RH (1986) Identification of a cyclic AMP-responsive element within the rat somatostatin gene. Proc Natl Acad Sci USA 83:6682-6686. 
Nagamoto-Combs K, Piech KM, Best JA, Sun B, Tank AW (1997) Tyrosine hydroxylase gene promoter activity is regulated by both CRE and AP1 sites following calcium influx: evidence for CREB-independent regulation. J Biol Chem 272:6051-6058.

Qi Y, Wang JKT, McMillian M, Chikaraishi DM (1997) Characterization of a CNS cell line, CAD, in which morphological differentiation is initiated by serum deprivation. J Neurosci 17:1217-1225.

Rios M, Sasaoka T, Chikaraishi DM, Roffler-Tarlov S (1995) The creation of a tyrosine hydroxylase-null mutation. Soc Neurosci Abstr 21:1780.

Schubert D, Heinemann S, Carlisle W, Tarikas H, Kimes B, Patrick J, Steinbach JH, Culp W, Brandt BL (1974) Clonal cell lines from the rat central nervous system. Nature 249:224-227.

Seif R, Cuzin F (1977) Temperature-sensitive growth regulation in one type of transformed rat cells induced by the tsa mutant of polyoma virus. J Virol 24:721-728.

Stachowiak MK, Goc A, Hong J-S, Poisner A, Jiang J-K, Stachowiak EK (1994) Regulation of tyrosine hydroxylase gene expression in depolarized nontransformed bovine adrenal medullary cells: second messenger systems and promoter mechanisms. Mol Brain Res 22:309-319.

Stewart MJ, McBride SM, Winter L, Duester G (1990a) Promoters for the human alcohol dehydrogenase genes $\mathrm{ADH} 1, \mathrm{ADH} 2$, and $\mathrm{ADH} 3$ : interaction of CCAAT/enhancer-binding protein with elements flanking the ADH2 TATA box. Gene 90:271-279.

Stewart MJ, Shean ML, Duester G (1990b) Trans-activation of human alcohol dehydrogenase gene expression in hepatoma cells by $\mathrm{C} / \mathrm{EBP}$ molecules bound in a novel arrangement just $5^{\prime}$ and $3^{\prime}$ to the TATA box. Mol Cell Biol 10:5007-5010.

Suri C, Fung BP, Tischler AS, Chikaraishi DM (1993) Catecholaminergic cell lines from the brain and adrenal glands of tyrosine hydroxylase -SV40 T antigen transgenic mice. J Neurosci 13:1280-1291.

Tank AW, Bowyer JF, Carlson CD, Fossom LH, Signs SA (1990) Regulation of tyrosine hydroxylase mRNA in rat pheochromocytoma cell lines. In: Catecholamine genes (Joh TH, ed), pp 81-99. New York: Wiley-Liss.

Weis L, Reinberg D (1992) Transcription by RNA polymerase II: initiator-directed formation of transcription-competent complexes. FASEB J 6:3300-3309.

Wong SC, Moffat MA, O'Malley KL (1994) Sequences distal to the AP-1/E-box motif are involved in cell type-specific expression of the rat tyrosine hydroxylase gene. J Neurochem 62:1691-1697.

Yoon SO, Chikaraishi DM (1992) Tissue-specific transcription of the rat tyrosine hydroxylase gene requires synergy between an AP-1 motif and an overlapping E-box containing dyad. Neuron 9:55-67.

Yoon SO, Chikaraishi DM (1994) Isolation of two E-box binding factors that interact with the rat tyrosine hydroxylase enhancer. J Biol Chem 269:18453-18462.

Zhou Q-Y, Quaife CJ, Palmiter RD (1995) Targeted disruption of the tyrosine hydroxylase gene reveals that catecholamines are required for mouse fetal development. Nature 374:640-643. 